\title{
Expulsion of the Placenta before the Birth of the Child.*
}

\author{
By Wм. D. Macfarlane, Jun., M.B. and C.M., \\ Surgeon to the Royal Samaritan Hospital for Women, Glasgow.
}

Spontaneous expulsion of the placenta before the birth of the child is rare. In very exceptional cases the placenta becomes separated from its attachment during the course of an otherwise normal labour, and is extruded in front of the child. In the Archiv f. Gyn., 1888, vol. xxxiii, pp. 486-497, Münchmeyer reports a case of prolapse of the placenta which had been normally situated. Stern, in the Monatsschrift f. Geburts. u. Gyn., Bd. 27, p. 685, reports a case where the sudden loss of intrauterine tension produced the premature separation of the placenta. The placenta in the case he mentions was discovered on vaginal examination lying free and low down in the lower segment of the uterus, and would most easily have been expelled had Nature been allowed full play. The presentation was a transverse one, and the anomaly was discovered when the patient was being artificially delivered. If the placenta be attached to the fundus uteri, the sudden loss of the liquor amnii and disease of the endometrium may cause a prolapse and premature expulsion of the placenta. Doubtless most of the recorded cases were examples of placenta prævia, and in the three cases I record I think the placenta was prævia, judging from the site of rupture in the membranes being in close proximity to the placenta.

CASE r. Mrs. A., aged 38, viii-para (all labours normal), had been under my care for several months for a chronic metro-endometritis. Menorrhagia, acquired dysmenorrhœa, and profuse mucopurulent discharge from a markedly catarrhal cervix were the chief symptoms. The uterus was curetted, and ichthyol 10 per cent. and glycerine vaginal tampons were used for several weeks. Liq. extract of ergot and hydrastis canaden. were administered internally, accompanied by the use of saline laxatives, and marked local and constitutional improvement resulted. I did not see the patient for six months, when she reported herself as being four months pregnant, and in good health. I saw her again at the end of her seventh month of pregnancy. She was then in excellent health, and the fœetal movements were the only occasion of complaint; her urine was free from albumen and remained so. During the thirty-sixth week of her pregnancy I was hurriedly summoned to see her, and found that she had suddenly been seized with pain which she said was like ordinary labour pain; this had lasted for about

* Read before the Glasgow Obstetrical and Gynæcological Society. 
a quarter of an hour, being alternately very severe and less so. Then there was a sudden and profuse discharge of water, accompanied by something protruding from the vagina. Judging from the great quantity of water on the floor where she had been standing, and the soakage of the bedclothes, hydramnios must have been present. (In examining the patient I found the placenta lying on the bed. There had been no vaginal bleeding-the head of the child was filling a half-dilated cervix. I allowed the patient to deliver herself, and this was accomplished in two and a half hours after the birth of the placenta.

The patient had considered herself in good health throughout her pregnancy; there had been no hæmorrhages at any time, and she did not think her labour was proceeding till the sudden pain, rupture of the membranes with, as she described, great loss of water, and the expulsion of the placenta occurred. The child was well-developed and healthy. The condition of the placenta is of special interest; its longest measurement was $11 \frac{3}{4}$ inches, and at no part was its thickness half an inch. Around the margin of the placenta, on its materual surface, were white infarcts, varying from the size of a split pea to that of a horse-bean, aud this condition extended round the margin of the placenta for about three-quarters of its circumference; there were also numerous infarets on the maternal surface other than at the margin.

Case II. Mrs. B., aged :4, v-jara (all labours normal), had been under treatment for many months for metrorrbagia, backache and symptoms of a chronic metro-endometritis. Local treatment as detailed in Case $i$, without uterine curettage, had removed her symptoms, and some months afterwards she became pregnant. All went well with her until her twenty-eighth weck of preguancy, when labour ensued without any appreciable cause. Her labour pains had been in evidence for little over an hour when the membranes ruptured. From the extraordinary loss of liquor amnii there was no doubt as to the presence of hydramnios. I examined her per vaginam and found the placenta presenting at the vulva. I left the case to natural delivery, which took place in $3 \frac{1}{2}$ hours after the expulsion of the placeuta. The child had evidently been dead for some days as evidenced by characteristic changes. The nother declared she felt the movements of the child markedly just before the rupture of the menbranes; an instance of how often the patient's sensations do not truly interpret the condition of affairs. Here again, as in Case $i$, there had been no bleeding, and there was none accompanying the separation of the placenta. The formation of the placenta was nornal. Numerous small red infarcts were along the maternal surface of the placenta and also in its substance.

Case IIr. Mrs. C., aged 28, multipara, had an interesting obstetric history. Her first child was born at tern, a year after 
marriage. The child was healthy and lived. Her second child was born eighteen months after the first child; the birth was premature (seventh month), and the child lived only a few hours. Both labours were natural. Six months after this she aborted at the second month of her pregnancy, and the uterus was curetted three months later on account of profuse menorrhagia. Shortly after this curettage she again became pregnant, and the pregnancy was interrupted at the end of the sixth month for free uterine bleeding dependent upon a marginal insertion of the placenta. Her uterine condition gave considerable trouble from the menorrhagia which existed. The uterus was again curetted and the endometrium revealed all the microscopical conditions of a simple adenoma. There was no adnexal disease, no kidney disease, and no specific history in either parent. Both parents were of a distinctly strumous type. After many months of care and treatment the constitutional and local conditions became markedly improved, and she became again pregnant. Matters proceeded normally till the beginning of the thirty-second week, when labour began and the membranes ruptured early. When I saw the patient I found her in bed, and the placenta was lying on the clothes. The cervix was not fully dilated, and accordingly labour was allowed to proceed naturally and terminated in three hours from the birth of the placenta. Along the periphery of the placenta were numerous white infarctions and three comparatively recent incapsulated hæmorrhages in the substance of the placenta and situated close to the placental margin on the maternal surface. In this case there was no hæmorrhage before or after the birth of the placenta.

The points of interest in these three cases are :-

(1) The premature expulsion of the placenta and in all pointing to placenta prævia, and in Case iii the last two pregnancies were placenta previa.

(2) The shape and unusual length of the placenta in two of the cases. It is not unusual to have the placenta crescentic in shape when situated near the os internum.

(3) The uniform presence of areas of placental infarction on the maternal surface.

(4) The presence of hydramnios in two of the cases.

(5) A history of endometrial involvement in all the cases.

(6) The absence of hæmorrhage either before or after the expulsion of the placenta.

The puerperium in these three cases was normal.

In the selected obstetrical works of Sir James Y. Simpson (pp. 188-193) there is an article on "Notes of 141 Cases in which the Expulsion or Extraction of the Placenta preceded that of the Child." He draws the following conclusions from a study of these cases in which the placenta was prævia:- 
1. The complete separation and expulsion of the placenta before the birth of the child in cases of unavoidable hæmorrhage is not so rare an occurrence as accoucheurs appear generally to believe.

2. It is not by any means so serious and dangerous a complication as might $a$ priori be supposed.

3. In 19 cases out of 20 in which it happened the attendant hæmorrhage has either at once altogether been arrested, or it has been so much diminished as not afterwards to be alarming.

4. The presence or absence of flooding after the complete separation of the placenta does not seem in any degree to be regulated by the duration of the time between the detachment of the placenta and the birth of the child.

The morbid condition of the placenta, viz., that of infarct formation, is the most frequent pathological change in placental tissue. It is the results of degenerative changes, which have been variously designated placentitis, hepatization, scirrhus, fatty degeneration, etc. These infarctions, most commonly appearing as white nodes, are examples of a fibrous degeneration, due according to the researches of Whitridge Williams, Ackerman, Orth and Eden, to an endarteritis of the vessels of the villi, a coagulation necrosis and the formation of canalized fibrin. Whitridge Williams states, as regards their frequency, that minute infarcts are to be found in every placenta, while similar areas, measuring $1 \mathrm{~cm}$. or more, were obtained in 65 per cent. of 500 consecutive placentæ examined. The red infarct is rarer than the white, and is stated to have some association with albuminuria. In the mother this was present in 33, 60, 67 per cent. of cases collected by Cagny, Rossier and Martin. In Case ii with red infaret formation there was no albuminuria at any period of the pregnancy. These red infarcts are of greater clinical significance than the white formations, and are frequently associated with imperfect development of the fœtus, and are at times a cause of death of the child.

Red infarctions are areas of placenta of a pinkish colour, irregular in shape, hard in consistency, and well defined from the normal tissue; they are generally situated on the maternal surface and occasionally in the substance of the placenta. Marked fibrous degeneration of the placenta associated with infarction interferes with the most important vital functions of the placenta, and if this pathological condition is widely distributed through the placenta the life of the fotus is seriously endangered. In the three cases reported the evidently pronounced placental changes probably contributed to the easy and premature detachment of the placenta. There was no suspicion, in any of these cases, of specific disease, and the placentæ in no respect were like those one is accustomed to find associated with syphilis. 